\title{
Prevalence of hypothyroidism in pregnancy and its feto-maternal outcome
}

\author{
Sharma V. ${ }^{1}$, Shukla N. ${ }^{2}$ \\ ${ }^{1}$ Dr. Varuni Sharma, Department of Obstetrics \& Gynaecology, ${ }^{2}$ Dr. Navin Shukla, Department of Otorhinolaryngololgy \\ \& Head \& Neck Surgery, both authors are affiliated with Subharti Medical College, Dehradun, Uttarakhand, India. \\ Correspondence Author: Dr. Varuni Sharma, Department of Obstetrics \& Gynaecology, Subharti Medical College, \\ Dehradun, Uttarakhand, India. E-mail: drvarunishukla@gmail.com
}

\begin{abstract}
Background: Thyroid disorders are among the most common endocrine disorders in pregnant females. Hypothyroidism is more common during pregnancy than hyperthyroidism. The overall prevalence of subclinical hypothyroidism in general population has been reported to be $4 \%-8.5 \%$ while overt hypothyroidism is $0.2-0.3 \%$ (2). Objective: To evaluate the prevalence of hypothyroidism in pregnancy and to determine association of feto-maternal outcome with hypothyroidism. Material and Methods: A Prospective study conducted over 120 patients who came to routine antenatal care and/or admitted in labour room of Subharti Hospital, Dehradun over a period of 01 year. Women with singleton pregnancy irrespective of the period of gestation were randomly selected for the study. Patients thus selected were divided into two groups: Control Group: This comprised of pregnant females in whom serum TSH and FT4 levels were found to be within normal range on estimation. Study Group: This group included pregnant females who were diagnosed as cases of subclinical hypothyroidism on the basis of raised TSH and normal TF4 levels and overt hypothyroidism on basis of raised TSH and decreased TF4. Results: The prevalence of hypothyroidism came out to be $24.29 \%$. Higher rate of still births, hyperbilirubinemia and admission to neonatal ICU (foetal distress, meconium stained liquor) in the hypothyroid group were observed. Conclusion: Hypothyroidismcontinues to be an important medical condition in pregnancy with significant feto-maternal morbidity. Due to the adverse effect of maternal thyroid disorder on maternal and fetal outcome, timely diagnosis and initiation of treatment of hypothyroid disorders is essential.
\end{abstract}

Keywords: Thyroid Dysfunction, Thyroid disorder, Pregnancy, Hypothyroidism, Outcome

\section{Introduction}

Thyroid disorders are among the most common endocrine disorders in pregnant females. Hypothyroidism is more common during pregnancy than hyperthyroidism [1]. Pregnancy is associated with significant but reversible changes in maternal thyroid physiology that can lead to confusion on the diagnosis or evaluation of thyroid abnormalities. Subclinical hypothyroidism is defined as increase in serum TSH usually $(4-10 \mathrm{Mu} / \mathrm{L})$ associated with normal concentration of serum thyroxine and triiodothyronine.

Overt hypothyroidism is diagnosed when high serum thyrotropin level is accompanied by abnormal low thyroxine level. The overall prevalence of subclinical hypothyroidism in general population has been reported

Manuscript received: $20^{\text {th }}$ December 2018

Reviewed: $30^{\text {th }}$ December 2018

Author Corrected: $6^{\text {th }}$ January 2019

Accepted for Publication: $10^{\text {th }}$ January 2019 to be $4 \%-8.5 \%$ while overt hypothyroidism is $0.2-$ $0.3 \%$ [2] Women with hypothyroidism can still conceive, although infertility rates are higher and failure of in vitro fertilization is more likely. Pregnant women with hypothyroidism have a greater risk of early and late obstetric complications such as miscarriage, anaemia, gestational hypertension, placental abruption, premature delivery, post-partum haemorrhage and admission of their baby to neonatal intensive care (particularly for RDS)[3].

The detrimental effects of maternal thyroid deficiency on foetal development are thought to depend on the severity and early onset of a reduced availability of maternal thyroid hormones. Recent studies indicate that undiagnosed (and hence untreated) hypothyroidism during the first half of pregnancy is associated with a risk of poorer neurodevelopment outcome in the progeny [4]. 


\section{Original Research Article}

Considering the wide-spread clinical implications of gestational sub \& - clinical hypothyroidism and its sequelae, this study was planned to know the prevalence of hypothyroidism in pregnant women attending the antenatal care at Department of Obstetrics \& Gynaecology of Subharti Hospital, Dehradun.

\section{Material and Methods}

Thestudy was conducted over 120 patients who came to routine antenatal care or were admitted in labour room of Subharti Hospital, Dehradun over a period of one year (from 1st May 2015 to 30th April 2016).

Study design: Prospective study

\section{Inclusion criteria}

Among the pregnant women who attended antenatal clinic or were admitted in labour room, women with singleton pregnancy irrespective of the period of gestation were randomly selected for the study. Patients were divided into two groups:

1. Control Group: This comprised of pregnant females in whom serum TSH and FT4 levels were found to be within normal range on estimation.

2. Study Group: This group included pregnant females who were diagnosed as cases of subclinical hypo-thyroidism on the basis of raised TSH and normal TF4 levels and overt hypothyroidism on basis of raised TSH and decreased TF4. 10 cases were diagnosed as hypothyroid but had pregnancy loss were dropped out from the study as they could not be followed for maternal and fetal outcome

\section{Exclusion criteria}

1. Already diagnosed hypothyroidism.

2. Multiple pregnancy

3. Women on treatment for thyroid dysfunction

4. Any medical co morbidity
Study Protocol- All patients were registered at their first antenatal visit. At the time of registration detailed history was taken and general examination was done.

Blood was taken for estimation of S.TSH and FT4. Hb, $\mathrm{ABO}, \mathrm{Rh}, \mathrm{RBS}, \mathrm{HIV}, \mathrm{HBs} \mathrm{Ag}$ and urine R/M were done as a part of routine test.

Normal values taken in the present:

TSH:0.465-5.68 mIU/ml

FT4:10.0-28.2 pmol/L

After registering the patients, theywere followed up with routine antenatal visits up to delivery and records were reviewed for any signs of development of PIH, preterm delivery, low birth weight, placental abruption, recurrent pregnancy losses, still birth, congenital anomalies, admission of baby to neonatal ICU, foetal distress in labour and hyperbilirubinemia.

Estimation of TSH- The TSH assay was performed using the TSH reagent Pack and Immuno diagnostic products $\mathrm{TSH}$ Calibrators on the ECi. Immunodiagnostic System.

An immunometric assay technique was used. Serum, EDTA or heparin plasma was recommended.

Estimation of free T4- The free T4 assay was performed using the free $\mathrm{T} 4$ calibrators on the $\mathrm{ECi}$ Immunodiagnostic system.

Statistical Analysis- For statistical analysis Percentage, Proportion, Chi square test were used. Once the values of chi square-tests are calculated the corresponding values of ' $p$ ' will be obtained using the standard tales are per degree of freedom and the significance graded as:

p value Results significance

$<0.05$ to $0.01 \quad$ statistically significant

\section{Results}

Table-1: Distribution of cases according to association with PIH in patients.

\begin{tabular}{|c|c|c|c|c|}
\hline \multicolumn{2}{|c|}{ Variable } & $\begin{array}{c}\text { Control group } \\
(\mathbf{n}=81)\end{array}$ & Study group $(\mathbf{n = 1 9 )}$ & \multirow{2}{*}{ P Value } \\
\hline \multirow{2}{*}{ PIH } & Present & $17(20.9 \%)$ & $9(47.36 \%)$ & \multirow{2}{*}{0.01} \\
\cline { 2 - 4 } & Not present & $64(79.1 \%)$ & $10(52.63 \%)$ & \\
\hline
\end{tabular}

The patients ( $\mathrm{n}=100)$ were divided into 2 groups: Control group \& Study group. In control group, 17 (20.90\%) of patients had PIH whereas in study group $9(47.36 \%)$ had PIH. The difference between both groups was statistically significant in relation to the presence/absence of $\mathrm{PIH}$. 
Original Research Article

Table-2: Association of hypothyroidism with Bad Obstetric History \& Diabetes.

\begin{tabular}{|c|c|c|c|c|}
\hline \multicolumn{2}{|c|}{ Risk Factor } & $\begin{array}{c}\text { Control group } \\
(\mathbf{n = 8 1})\end{array}$ & $\begin{array}{c}\text { Study group } \\
(\mathbf{n}=19)\end{array}$ & \multirow{2}{*}{ P Value } \\
\hline \multirow{2}{*}{$\begin{array}{c}\text { Bad obstetric } \\
\text { history }\end{array}$} & Present & $13(16.04 \%)$ & $7(36.84 \%)$ & \multirow{2}{*}{0.04} \\
\cline { 2 - 4 } & Not present & $68(83.95 \%)$ & $12(63.16 \%)$ & $<0.05$ \\
\hline \multicolumn{5}{|c|}{} \\
\hline \multirow{2}{*}{ Diabetes } & Present & $1(1.23 \%)$ & $2(10.5 \%)$ & \multirow{2}{*}{} \\
\cline { 2 - 4 } & Not present & $80(98.76 \%)$ & $17(89.47 \%)$ & \\
\hline
\end{tabular}

Table 2 shows the relationship of screening for detection of hypothyroidism with high risk factor. Out of 100 patient underwent screening, 13 patients from control group and 7 patients from study group showed risk factor such as, bad obstetrics history such as still birth or recurrent abortions. Diabetes was present in 1 patient from control group and in 2 patients from study group.

On statistical analysis the correlation was found to be significant $(\mathrm{p}<0.05)$ patients with history of Type-I DM and BOH.

Table-3: Distribution of cases according to association with placental abruption.

\begin{tabular}{|c|c|c|c|c|}
\hline \multicolumn{2}{|l|}{ Variables } & $\begin{array}{l}\text { Control group } \\
(n=81)\end{array}$ & $\begin{array}{l}\text { Study group } \\
(n=19)\end{array}$ & P Value \\
\hline \multirow{2}{*}{ Placental abruption } & Present & $7(8.68 \%)$ & $4(21.1 \%)$ & \multirow{2}{*}{0.119} \\
\hline & Absent & $74(91.35 \%)$ & $15(78.9 \%)$ & \\
\hline \multirow{2}{*}{ Mode of delivery } & Vaginal delivery & $65(80.24 \%)$ & $11(57.89 \%)$ & \multirow{2}{*}{$<0.05$} \\
\hline & Caesarean & $16(19.76 \%)$ & $8(42.11 \%)$ & \\
\hline \multirow{2}{*}{$\begin{array}{c}\text { Gestational age of } \\
\text { delivery }\end{array}$} & $<34$ weeks & $8(9.87 \%)$ & $8(42.11 \%)$ & \multirow{2}{*}{0.03} \\
\hline & $>34$ weeks & $73(90.12 \%)$ & $11(57.89 \%)$ & \\
\hline \multirow{3}{*}{$\begin{array}{c}\text { Incidence of low birth } \\
\text { weight }\end{array}$} & $<2 \mathrm{~kg}$ & $5(6.17 \%)$ & $6(31.6 \%)$ & $<0.002$ \\
\hline & $2-2.5 \mathrm{~kg}$ & $46(56.8 \%)$ & $9(47.1 \%)$ & $<0.005$ \\
\hline & $>2.5 \mathrm{~kg}$ & $30(37.1 \%)$ & $4(21.1 \%)$ & $\mathrm{P}>0.05$ \\
\hline
\end{tabular}

Comparing the control group and study group on the basis of distribution of cases, Placental abruption was present in 7 (8.68\%) patients of control group and $4(21.1 \%)$ patients of study group. There was a statistically significant difference observed in Vaginal delivery and Caesarean of both groups with $\mathrm{p}$ value $<0.05$ also, the difference was significant for gestational age of delivery $<34$ weeks $\&>34$ weeks in both groups. As per the incidence of low birth weight, 5 patients of Control group \& 6 patients of study group has weight $<2 \mathrm{~kg}, 46$ patients of Control group \& 9 patients of study group has weight $2-2.5 \mathrm{~kg}, 30$ patients of Control group \& 4 patients of study group has weight $>2.5 \mathrm{~kg}$.

Table-4: Relationship of hypothyroidism with foetal distress in labour.

\begin{tabular}{|c|c|c|c|}
\hline Variables & $\begin{array}{c}\text { Control group } \\
(\mathbf{n = 8 1 )}\end{array}$ & $\begin{array}{c}\text { Study group } \\
(\mathbf{n = 1 9 )}\end{array}$ & P Value \\
\hline Foetal distress, MSAF \& other & $25(30.86 \%)$ & $9(47.36 \%)$ & $<0.05$ \\
\hline No foetal distress & $56(69.13 \%)$ & $10(52.63 \%)$ & \\
\hline
\end{tabular}

Foetal distress, MSAF was observed in 25 patients of control group and in 9 patients of study group. On statistical analysis the result was found to be significant $\mathrm{P}<0.05$. 
Original Research Article

Table-5: Neonatal outcomes in patients with hypothyroidism in comparison to normal patients

\begin{tabular}{|c|c|c|c|}
\hline Outcome & $\begin{array}{c}\text { Control group } \\
(\mathbf{n = 8 1})\end{array}$ & $\begin{array}{c}\text { Study group } \\
(\mathbf{n = 1 9 )}\end{array}$ & P Value \\
\hline Still birth & $2(2.46 \%)$ & $3(15.8 \%)$ & $<0.05 \mathrm{Z}=1.81$ \\
\hline Congenital anomaly & $0(0 \%)$ & $1(5.3 \%)$ & $>0.05$ \\
\hline Admission to ICU & $14(17.3 \%)$ & $8(42.1 \%)$ & $<0.05 \mathrm{Z}=2.03$ \\
\hline Hyperbilirubinemia & $9(11.11 \%)$ & $6(31.57 \%)$ & $<0.05$ \\
\hline
\end{tabular}

On statistical analysis the incidence of still births and ICU admission rates \& hyperbilirubinemia were found to be significant between two groups.

\section{Discussion}

Considering the widespread clinical implications of gestational hypothyroidism and its sequelae, the present study was aimed to study the prevalence of hypothyroidism in pregnancy and its feto-maternal outcomes. The study was carried out on 107 patients, who presented to antenatal care in Subharti Hospital Dehradun over a period of one year from $1^{\text {st }}$ May 2015 to $30^{\text {th }}$ April 2016.

The women were followed up till delivery. The study population consisted of 81 normal patients and 19 hypothyroid patients diagnosed and followed up. 7 hypothyroid patients were dropped out from study. In our study, the prevalence of hypothyroidism came out to be $24.29 \%$ while in a study by Saki F et al. found the prevalence of hypothyroidism $13.7 \%$ out of which $2.4 \%$ was clinical and $11.3 \%$ was sub-clinical [5].

Another study by Sahu HT et al. noted that the prevalence of thyroid dysfunction was high, with subclinical hypothyroidism in $6.47 \%$ and overt hypothyroidism in $4.58 \%$ women [6]. The variation in prevalence of hypothyroidism may be due to difference in defined normal range of TSH.

Considering the distribution of cases in study population, in the study group, 19 women were included, these were the women who were diagnosed as hypothyroid on the basis of serum TSH and Free $\mathrm{T}_{4}$ levels. In control group, 81 women who had normal thyroid function test on screening. They included the remaining 81 patients of study population.

\section{Distribution of cases according to association with PIH}

The present study shows $47.36 \%$ cases of PIH in patients diagnosed as hypothyroidism patients in study group compared to $20.9 \%$ incidence of PIH in patients in control group ( $\mathrm{P}$ value 0.01- significant). Similar results were observed by Sahu HT, Das V Mittal et al (2010), Aziz Nuzhat et al. in 2006, Kumar Ashok, Ghosh B.K. et al $[6,7,8]$.

\section{Relationship of Screening for hypothyroidism with individual high risk factors}

Positive correlation was found between risk factors as bad obstetric history and Type - I diabetes. 35\% with $\mathrm{BOH}$ developed hypothyroidism which was statistically significant with $\mathrm{P}<0.05 .16$ patients, out of 19 hypothyroid patients in the study group had one or the other risk factor, whereas 3 patients $(15.78 \%)$ were without any risk factors.De vivo et al also found that the occurrence and timing of pregnancy loss is related to hypothyroidism [9]. Bijay Viadyaet al. showed that the prevalence of raised TSH was higher in the high risk group [10].

Study by Brain M. Casey, Jodi S. Dash et al in 2005 showed that pregnancy in women with subclinical hypothyroidism was three times more likely to be complicated by placental abruption when compared with healthy pregnant women [11]. Similar results were shown by Goel $\mathrm{P}$, et al in their study on 30 patients with subclinical hypothyroidism in 2005. They found an incidence of $0.3 \%$ placental abruption in their study group which was not significant[12].

Comparison of mode of delivery in the control and study groups

In the present study, we found that 8 out of $19(42.11 \%)$ in the study groupcompared to 16 of $81(19.76 \%)$ patients in the control group were delivered by caesarean section as on statistical analysis the difference was significant $(\mathrm{p}<0.05)$.

Comparable results were shown in a study by Sahu HT, Das V Mittal et al (2010), Iskandar Idris, Ramalingam Srinivasan et al. in 2005 [6,13]. 


\section{Original Research Article}

\section{Comparison of preterm birth in control and study group}

The present study showed preterm birth defined as delivery before 34 weeks $42.11 \%$ in the study group compared to $9.87 \%$ of controls, which was found to be statistically significant with $\mathrm{p}<0.05$ ( $\mathrm{p}$ value 0.003 ). Study by Brain M. Casey, Jodi S et al in 2005 Aziz Nuzhat, Reddi Pranathi et al in 2006 also showed increased incidence of preterm delivery in hypothyroid group [7,14].

\section{Comparison of cases according to birth weights}

The present study showed significant proportion of babies having low birth weight $31.6 \%$ of infants weighed $<2.0 \mathrm{~kg}$ in the study group as compared to $6.17 \%$ of the control group (p value 0.002 ). Similar results were observed in studies conducted by Aziz Nuzhat et al., Idris I., Srinivasan et al[7,13]. Another similar study by Goel P et al. showed $13.3 \%$ incidence of low birth weight with $20 \%$ evidence of foetal distress[12].

\section{Comparison of cases according to fetal distress}

The present study showed $47.36 \%$ of study group having foetal distress in labour, 3 babies out of 19 had still birth that is $15.8 \%$ and 1 out of 19 had congenital anomalies i.e.5.3\%. The foetal distress was found to be significant $(\mathrm{p}<0.05)$ in relation to the control group and were comparable to the studies by Brain M Casey et al.which showed that admission to the neonatal intensive care nursery and respiratory distress were twice as likely in infants delivered of women with sub clinical hypothyroidism [14]. Another similar study by Goel P et al. observed $13.3 \%$ incidence of low birth weight and $20 \%$ had evidence of foetal distress [12].

Considering the above feto-maternal complications the most practical approach is to screen all pregnant women for hypothyroidism as early in pregnancy as possible (on before conception). In the case of the mother, screening would result in early diagnosis and treatment of hypothyroidism. The implications are staggering when one considers that there is a significant increase in intrauterine deaths, spontaneous abortions, premature births and pre-eclampsia in women with gestational hypothyroidism.

In the infant, major malformation and loss of IQ could be prevented by early diagnosis and treatment of the mother. It is believed that if screening of all pregnant women in implemented, the mother, the infant and society will all benefit.

\section{Conclusion}

A total of 107 patients were included in the study and were screened by estimation of serum TSH and FT4 to determine the presence of hypothyroidism. Only 100 women were followed up from their antenatal visit up till delivery Feto-maternal outcome of these patients was recorded, while 7 were dropped out because of early pregnancy loss. The salient observations made in this study are as follows:

- The prevalence of hypothyroidism was $24.29 \%$ in this study.

- The present study concluded that history of recurrent pregnancy loss and diabetes are significantly associated with hypothyroidism.

- The study showed that there was increased rate of gestational hypertension, preeclampsia, preterm delivery and low birth weight babies in hypothyroid group which was statistically significant.

- The study also showed that rate of foetal distress during labour (47.36\% Vs $30.86 \%$ ) was also high and hence rate of emergency caesarean section $(42.11 \mathrm{Vs}$ $19.76 \%$ ) was high in hypothyroid group. This value is also statistically significant.

- The study also showed that there was higher rate of still births, hyper bilirubinaemia and admission to neonatal ICU (foetal distress, meconium stained liquor) in the hypothyroid group.

\section{What this study adds to existing knowledge}

The present study therefore concludes that hypothyroidism continues to be an important medical condition in pregnancy with significant feto-maternal morbidity. This study therefore recommends that early identification and proper management of this condition is the only intervention to ameliorate and decrease is attendant morbidity and mortality.

Funding: Nil, Conflict of interest: Nil

Permission from IRB: Yes

\section{References}

1. Ross DS. Serum thyroid-stimulating hormone measurement for assessment of thyroid function and disease. Endocrinol Metab Clin North Am. 2001 Jun;30(2):245-64, vii.

2. McLeod D, McIntyre H. Subclinical hypothyroidism and related biochemical entities in pregnancy: implications and management. Obstetric Medicine. 2010;3(4):139-144. 


\section{Original Research Article}

3. Tudosa R, Vartej P, Horhoianu I, Ghica C, Mateescu $\mathrm{S}$, Dumitrache I. Maternal and fetal complications of the hypothyroidism-related pregnancy. Maedica (Buchar). 2010; 5(2):116-123.

4. Kumar A, Singh R, Prasad S. Hypothyroidism during pregnancy. International Journal of Gynecology \& Obstetrics. 2003;84(3):252-253.

5. Saki F, Dabbaghmanesh M, Ghaemi S, Forouhari S, Ranjbar Omrani G, Bakhshayeshkaram M. Thyroid Function in Pregnancy and Its Influences on Maternal and Fetal Outcomes. International Journal of Endocrinology and Metabolism. 2014;12(4).

6. Sahu MT, Das V, Mittal S, et al. Overt and subclinical thyroid dysfunction among Indian pregnant women and its effect on maternal and fetal outcome. Arch Gynecol Obstet. 2010 Feb; 281(2):215-20. doi: 10.1007/s00404-009-1105-1. Epub 2009 May 13.

7. Nuzhat A, Pranathi R, Evita F. Hypothyroidism in pregnancy: Is universal screening needed? J Obstet Gynecol India. 2006;56(6):495-498.

8. Kumar A, Ghosh BK, Murthy NS. Maternal thyroid hormonal status in preeclampsia. Indian $\mathrm{J}$ Med Sci. 2005 Feb;59(2):57-63.
9. De Vivo A, Mancuso A, Giacobbe A, et al. Thyroid function in women found to have early pregnancy loss. Thyroid. 2010 Jun; 20(6):633-7. doi: 10.1089/thy.2009. 0323.

10. Vaidya B, Anthony S, Bilous M, et al. Detection of thyroid dysfunction in early pregnancy: Universal screening or targeted high-risk case finding? J Clin Endocrinol Metab. 2007 Jan;92(1):203-7. Epub 2006 Oct 10. DOI:10.1210/jc.2006-1748

11. Casey BM, Dashe JS, Wells CE, et al. Subclinical hypothyroidism and pregnancy outcomes. Obstet Gynecol. 2005 Feb;105(2):239-45.

12. Goel P, Radotra A, Devi K, et al. Maternal and perinatal outcome in pregnancy with hypothyroidism. Indian J Med Sci. 2005 Mar;59(3):116-7.

13. Idris I, Srinivasan R, Simm A, et al. Maternal hypothyroidism in early and late gestation: effects on neonatal and obstetric outcome. Clin Endocrinol (Oxf). 2005 Nov;63(5):560-5.

14. Casey BM. Subclinical hypothyroidism and pregnancy. Obstet Gynecol Surv. 2006 Jun; 61(6): 41520; quiz 423. DOI: 10. 1097/01.ogx. 0000223331. $51424.9 \mathrm{~b}$

\section{How to cite this article?}

Sharma V, Shukla N. Prevalence of hypothyroidism in pregnancy and its feto-maternal outcome. Obs Rev:J obstet Gynecol 2019;5(1):7-12.doi: 10.17511/joog.2019.i01.02. 